$$
\text { Pontifícia Universidade C Católica }
$$

Claudia Müller de Almeida

A Influência do Correio Eletrônico na Comunicação
Organizacional

Dissertação de Mestrado

Dissertação apresentada como requisito parcial para obtenção do grau de Mestre pelo Programa de Pósgraduação em Administração de Empresas do Departamento de Administração da PUC-Rio.

Orientador: Prof. José Roberto Gomes da Silva 


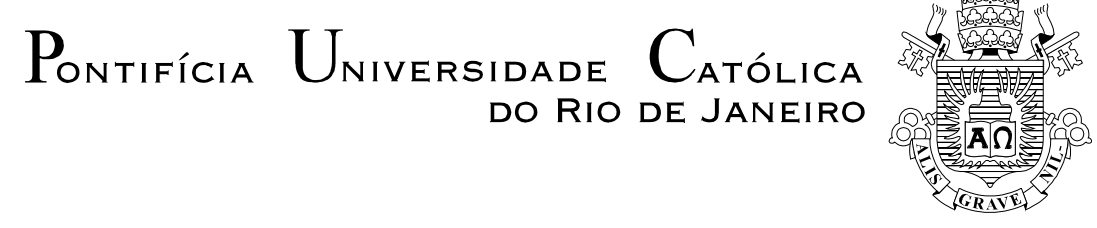

Claudia Müller de Almeida

\title{
A Influência do Correio Eletrônico na Comunicação \\ Organizacional
}

Dissertação apresentada como requisito parcial para obtenção do grau de Mestre pelo Programa de Pósgraduação em Administração de Empresas da PUCRio. Aprovada pela Comissão Examinadora abaixo assinada.

\author{
Prof. José Roberto Gomes da Silva \\ Orientador \\ Departamento de Administração - PUC-Rio
}

Prof. Maria do Carmo Leite de Oliveira Departamento de Letras - PUC-Rio

Prof. Ricardo Ferreira Freitas

Comunicação Social - UERJ

Prof. João Pontes Nogueira

Vice-Decano de Pós-Graduação do CCS

Rio de Janeiro, 21 de agosto de 2006 
Todos os direitos reservados. É proibida a reprodução total ou parcial do trabalho sem autorização da universidade, da autora e do orientador.

\section{Claudia Müller de Almeida}

Graduou-se em Comunicação Social/Jornalismo na PUC-Rio em 1997. Trabalhou de 1997 a 2000 no Instituto Gênesis da PUC-Rio, participando da estruturação do Instituto e das Incubadoras de Empresas, acompanhando o desenvolvimento de projetos de empreendedorismo e ajudando na formação de novas empresas. Em 2000, foi para o Banco Opportunity, onde trabalhou na holding Innovate como Editora de Conteúdo dos projetos. Voltou para o Instituto Gênesis em 2001, quando assumiu a Assessoria de Comunicação. Em 2002, cursou Especialização em Gestão e Recursos Humanos no IAG/PUC-Rio. Em 2002, tornou-se Gerente de Comunicação e RH. Em 2003, passou a ser Gerente de Ambiente e Imagem. Em 2004, tornou-se Gerente Executiva do Instituto Gênesis. Venceu o Prêmio Anprotec 2004, na categoria Projeto Inovador, com a elaboração e a coordenação do projeto "Atração de Recursos Humanos para as Empresas Residentes da Incubadora Gênesis". Em 2005, transferiu-se para o IAG - A Escola de Negócios da PUC-Rio, onde trabalha como Assistente de Pesquisa no IAG Corporate (área responsável pelos cursos incompany e pelas relações com empresas).

Ficha Catalográfica

Almeida, Claudia Müller de

A influência do correio eletrônico na comunicação organizacional / Claudia Müller de Almeida ; orientador: José Roberto Gomes da Silva. - Rio de Janeiro : PUC, Departamento de Administração, 2006.

$$
171 \mathrm{f.} ; 30 \mathrm{~cm}
$$

Dissertação (mestrado) - Pontifícia Universidade Católica do Rio de Janeiro, Departamento de Administração.

Inclui referências bibliográficas.

1. Administração - Teses. 2. Comunicação organizacional. 3. Correio eletrônico. 4. Colaboração. 5. Comportamento organizacional. II. Pontifícia Universidade Católica do Rio de Janeiro. Departamento de Administração. III. Título. 


\section{Agradecimentos}

Ao meu orientador, José Roberto Gomes, não apenas pela orientação, mas por todo o apoio no desenvolvimento do tema estudado nesta dissertação.

Aos meus colegas e amigos de trabalho, que tanto me incentivaram a seguir em frente e concluir este trabalho.

Aos profissionais entrevistados, por terem compartilhado comigo suas experiências e opiniões e, assim, me ajudado na realização desta pesquisa.

Aos meus colegas e amigos de Mestrado, que tanto me apoiaram em momentos difíceis, me fizeram rir e sorrir, acreditar e seguir em frente.

A todos com quem convivi nestes últimos três anos e que contribuíram direta ou indiretamente para a conclusão do meu curso e deste trabalho.

À minha família, pelo carinho e apoio, pela compreensão e atenção sempre presentes.

E àqueles que, sendo o que são, me inspiram a olhar adiante, a acreditar que vale a pena e a dar o melhor de mim nas coisas que faço. 


\section{Resumo}

Almeida, Claudia Müller de; Silva, José Roberto Gomes da (Orientador). A Influência do Correio Eletrônico na Comunicação Organizacional. Rio de Janeiro, 2006. 171p. Dissertação de Mestrado - Departamento de Administração, Pontifícia Universidade Católica do Rio de Janeiro.

A chegada da tecnologia da informação (TI) à realidade das pessoas aumentou a capacidade e a qualidade dos recursos técnicos de distribuição de informação e conhecimento. O correio eletrônico agiliza processos, facilita a troca de informações, e proporciona uma economia de tempo e dinheiro. Mas qual é o efeito nas relações de trabalho? As tecnologias podem facilitar os trabalhos em conjunto? É necessário pensar a comunicação organizacional como a possibilidade de interlocução entre colaboradores, e como um mecanismo de gestão colaborativa. Este trabalho visa a identificar qual é o papel do correio eletrônico na comunicação organizacional, decifrando as suas principais características de uso. A pesquisa realizada foi do tipo exploratória, com base em entrevistas com 15 pessoas que atuam em diferentes áreas e níveis hierárquicos de grandes e pequenas empresas. Como resultado deste trabalho, destaca-se a percepção de que o e-mail tornou-se um componente tido como indispensável à dinâmica das organizações e que os indivíduos verificam uma relação de "quase dependência” deste instrumento. No geral, ele é percebido como sendo um meio de comunicação prático, rápido, direto, objetivo e eficaz. A percepção é a de que o e-mail agiliza e flexibiliza o processo de trabalho. Mas há situações em que a comunicação presencial é necessária e não deve ser substituída, assim como o telefone. Dentre os aspectos que afetam positivamente a comunicação, os entrevistados destacaram o clima organizacional e o relacionamento interpessoal. Dentre os aspectos que afetam negativamente, a estrutura hierárquica muito rígida, a dificuldade e/ou a falta de integração entre as áreas da empresa aparecem como sendo os principais na opinião dos entrevistados.

\section{Palavras-chave}

Comunicação organizacional, correio eletrônico, colaboração, comportamento organizacional. 


\section{Abstract}

Almeida, Claudia Müller de; Silva, José Roberto Gomes da (Advisor). The Influence of the E-mail in the Organizational Communication. Rio de Janeiro, 2006. 171p. MSc. Dissertation - Departamento de Administração, Pontifícia Universidade Católica do Rio de Janeiro.

The arrival of the Information Technology (IT) to the reality of the people increased the quality and capacity of the technical resources for the distribution of information and knowledge. The e-mail speeds processes, facilitates the exchange of information, and provides for an economy of time and money. But what is its effect into the work relations? Can technologies facilitate the performance in work groups? It is necessary to think on the organizational communication as the possibility of interlocution between collaborators, and as a mechanism of collaborative management. This work aims to identify which is the function of the e-mail in the organizational communication, deciphering its main characteristics of use. This was an exploratory research, based on interviews with 15 people who act in different areas and hierarchic levels of big and small companies. As a result of this work, a distinguished perception that the e-mail became an indispensable component to the dynamics of organizations and that the individuals verify a relation of "almost dependence" to this instrument. In general, it is perceived as being a practical, fast, direct, objective and efficient media. The perception is that the e-mail speeds up and stretches the work process. But it has situations where the interpersonal communication is necessary and it should not have to be substituted, as well as the telephone. Amongst the aspects that affect the communication positively, the interviewed subjects depicted the organizational environment and the interpersonal relationship. Amongst the negative aspects, the very rigid hierarchic structure and the difficulty and/or lack of integration within the areas of the companies, were mentioned as being the main concern of the interviewed.

\section{Keywords}

Organizational communication, e-mail, contribution, organizational behavior. 


\section{Sumário}

1. Descrição do Problema 10

1.1. Introdução 10

1.2. Objetivos do Estudo 18

1.2.1. Objetivo Primário 18

1.2.2. Objetivos Intermediários $\quad 19$

1.3. Relevância do Estudo 20

1.4. Delimitações do Estudo 22

1.5. Estrutura da Dissertação 22

2. Comunicação Organizacional 24

2.1. Da Visão Instrumental ao Reconhecimento da Subjetividade 24

2.2. A Importância dos Meios $\quad 27$

2.3. Outros Fatores que Afetam a Comunicação Organizacional 30

2.4. O Conceito de Estilos de Comunicação 33

2.5. Diversas Leituras sobre a Comunicação 36

2.6. A Emergência das Tecnologias da Informação e da Comunicação nas Organizações 41

2.7. As Crenças no Poder das TICs 45

3. A Influência das TICs nas Relações Interpessoais e o uso do Correio Eletrônico nas Organizações $\quad 54$

3.1. O Papel das Relações Interpessoais na Constituição das Organizações 55

3.2. A Influência das TICs sobre as Relações Interpessoais nas Organizações

3.3. A Comunicação por Correio Eletrônico 63

3.4. Um Outro Lado da Comunicação por Correio Eletrônico 70

4. Metodologia do Estudo $\quad 81$

4.1. Tipo de Pesquisa $\quad 81$

4.2. Universo da Pesquisa e Critérios de Seleção 82

4.3. Coleta de Dados $\quad 84$

4.4. Análise dos Dados $\quad 90$

4.5. Limitações do Método 93

5. Resultados 95

5.1. O Correio Eletrônico como um Elemento Central nas Organizações 95

5.2. A Diferença na Comunicação entre Pequenas e Grandes Empresas 98

5.3. Os Principais Meios de Comunicação Utilizados na Empresa 100

5.4. A Comunicação por Correio Eletrônico - Vantagens e Desvantagens 109 
5.5. Correio Eletrônico x Comunicação Presencial 110

5.6. Correio Eletrônico x Telefone 115

5.7. Os Softwares de Mensagens Instantâneas 116

5.8. A Comunicação Formal nas Grandes Empresas 118

5.9. Rádio Corredor 120

5.10. Os Níveis Hierárquicos e a Comunicação por Correio Eletrônico 122

5.11. Papel ou Digital 124

5.12. Aspectos que Afetam a Comunicação nas Organizações 125

5.13. O Correio Eletrônico como Fator de Integração (ou Isolamento) das Pessoas nas Organizações 127

5.14. A Riqueza da Informação no Correio Eletrônico 131

5.15. Correio Eletrônico, Produtividade e Eficiência nos Processos de Trabalho 134

5.16. Rotina de Utilização do Correio Eletrônico 138

5.17. A Redação de Mensagens de E-mail 140

5.18. Cópia e Cópia Oculta de Mensagens 144

5.19. Sobrecarga de Informação 146

5.20. Como Melhorar o Uso do Correio Eletrônico 148

6. Conclusão 151

6.1. A Influência do Correio Eletrônico na Comunicação Organizacional 153

6.2. As Regras de Uso Consensadas 160

6.3. O Avanço da Tecnologia 162

6.4. Considerações Finais e Recomendações para Futuros Estudos 164

7. Referências bibliográficas 166 


\section{Lista de quadros}

Quadro 1 - Arquétipos comunicacionais, inspirado em Giordano (1998). 26

Quadro 2 - Arquétipos comunicacionais, inspirado em Giordano (1998). 83

Quadro 3 - Quadro de referência da revisão da literatura 86

Quadro 4 - Pontos positivos e negativos do correio eletrônico 154 